\title{
New corneal assessment index from the relational thickness and other OCULUS values (CAIRO Index)
}

This article was published in the following Dove Press journal:

Clinical Ophthalmology

\author{
Maged M Roshdy ${ }^{1,2}$ \\ Sherine S Wahba ${ }^{1,2}$ \\ Ramy R Fikry ${ }^{2,3}$ \\ 'Ophthalmology Department, Ain \\ Shams University, Cairo, Egypt; \\ ${ }^{2}$ Ophthalmology Department, \\ Al Watany Eye Hospital, Cairo, Egypt; \\ ${ }^{3}$ Ophthalmology Department, Cairo \\ University, Cairo, Egypt
}

\begin{abstract}
Purpose: The aim of this study was to find indices for keratoconus $(\mathrm{KC})$ detection with higher sensitivity and specificity than the currently available ones with the rotating Scheimpflug imaging (Oculyzer I, Pentacam) software.
\end{abstract}

Patients and methods: Data of 103 normal and $73 \mathrm{KC}$ eyes imaged by Oculyzer I, including slit-lamp examination, refraction, Scheimpflug images, and follow-up data were collected. Logistic regression was done to find new indices with higher area under receiver operating characteristic curves using the currently available ones.

Results: The Corneal Assessment Index from Relational thickness and other OCULUS Values 9 (CAIRO 9) index, deduced from the Ambrosio relational thickness-maximum and the anterior elevation at thinnest point from $9 \mathrm{~mm}$ best-fit sphere, and the CAIRO 8, deduced from Ambrosio relational thickness-maximum and anterior elevation at thinnest point from $8 \mathrm{~mm}$ best-fit sphere, have a very high area under receiver operating characteristic curves for KC detection (0.997 and 0.995, respectively).

Conclusion: New corneal assessment index is deduced with better sensitivity and specificity for $\mathrm{KC}$ detection.

Keywords: keratoconus, pentacam, keratoconus indices, elevation, pachymetry, keratoconus diagnosis

\section{Introduction}

The identification of apparently normal corneas that will develop ectasia after laser in situ keratomileusis (LASIK) is a challenge. The detection of the earliest form of subclinical keratoconus (KC) as a major risk factor could be done with corneal topography. ${ }^{1}$ Although Placido disk systems are accurate in many cases of $\mathrm{KC}$, there are significant limitations with the curvature map. The area of corneal coverage is limited to about $60 \%$ of the corneal surface, eliminating important data for many peripheral or paracentral pathologies. It gives no information about the posterior corneal surfaces. Moreover, the pachymetric maps representing the distribution of corneal thickness cannot be made. Additionally, there is a limitation in attempting to reconstruct the corneal surface based on curvature measurements. ${ }^{2,3}$

On the other hand, the addition of elevation-based tomography offers important advantages as it can image the posterior corneal surface and produce an accurate full surface pachymetric map. Elevation maps are also more accurate in determining the cone morphology and in identifying the false positive $\mathrm{KC}$ suspect, ${ }^{4}$ as early ectatic changes could manifest earlier in the posterior surface of the cornea and therefore, necessitate accurate imaging of both surfaces. ${ }^{5}$
Correspondence: Maged M Roshdy Ophthalmology Department, Ain Shams University, AI Watany Eye Hospital, 21 I Elhegaz St., Elhegaz Sq., Heliopolis, Cairo, Egypt

Tel +20 I22 28I I230

Fax +20 226247575

Email dr_maged_roshdy@med.asu.edu.eg $\mathrm{BY}$
hC for commercial use of this work, please see paragraphs 4.2 and 5 of our Terms (https://www.dovepress.com/terms.php). 
Tomography-derived pachymetric indices are better in differentiating normal from keratoconic corneas than single-point pachymetric measurements. ${ }^{6}$ One of the most valuable combined indices is the tomographic relational thickness metrics; Ambrosio relational thickness (ART) ${ }^{6}$ which represents the ratios of thinnest point pachymetry and the pachymetry progression index (PPI) values. It had statistically better diagnostic performance than single-point values to identify KC. ${ }^{7}$ Another valuable combined index is the multimetric D index, which had a good specificity. It is reported to be better than other single indices in diagnosing $\mathrm{KC}$ and subclinical KC. 8

It is a common practice to use combined indices to overcome the shortcomings of and get benefit of the strength of single indices. For example, KISA $\%,{ }^{9}$ keratoconus prediction index, and keratoconus index, ${ }^{10}$ topographic keratoconus grading, ${ }^{11}$ and even the ART itself. ${ }^{6}$ The aim of this study was to find new combined indices for early $\mathrm{KC}$ detection with higher sensitivity and specificity than the currently available with the rotating Scheimpflug imaging (Oculyzer, Pentacam) software aiming to reach the major goal of decreasing the risk factors for developing post-LASIK ectasia.

\section{Patients and methods}

A retrospective study was conducted in the time interval between June 2008 and December 2009 and the data were collected and evaluated. The patients' files were revised again in December 2015 for follow-up visits during this period to confirm the previous diagnosis made at the time of Pentacam scanning and hence to confirm the evaluated results. Patients were imaged by the Pentacam branded as Allegro Oculyzer (WaveLight, GmbH, Erlangen, Germany) with software version 1.16r12 at Al Watany Eye Hospital, Cairo, Egypt. Exclusion criteria included patients with previous ocular surgery, clinically detected corneal pathology other than $\mathrm{KC}$, and contact lens wear during the last 2 weeks.

Patients were classified according to the history, clinical examination, and topographic pattern into 2 groups; Group 1: 103 normal eyes and Group 2: 73 eyes with KC. Group 2 was further divided according to the Topographic Keratoconus Classification (TKC) into 2 subgroups; Group 2a of early KC: 23 eyes (TKC $<2$ [1 and $1-2]$ ) and Group $2 b$ of established $\mathrm{KC}: 50$ eyes $(\mathrm{TKC}=2-4)$.

Every eye was scanned at least thrice by the Allegro Oculyzer. Each scan included 25 Scheimpflug images. Data were collected from the most reliable scan as stated by the "QS" pop-up box (ie, largest analyzed area, valid data percent, and good alignment). The data were collected from the automatically displayed indices with the default reference surface and on choosing different reference surfaces shape (ie, best-fit toric ellipsoid [BFTE]) and different calculation areas (7, 8, or $9 \mathrm{~mm}$ ). Elevation values at thinnest point were displayed on mouse click at this point (Figure 1).

Only 1 eye from each patient was selected based on the more reliable scan, as previously described.

Logistic regression was done using the 10 indices with highest area under receiver operating characteristic curves (AUROC) from our previous work ${ }^{12}$ to find new indices with higher AUROC. The 10 indices included:

1. Elevation indices:

1. Elevation of the thinnest point from the $7 \mathrm{~mm}$ posterior (PE) best-fit sphere (BFS) (in $\mu \mathrm{m}$ ).

2. Elevation of the thinnest point from the 8 and $9 \mathrm{~mm}$ anterior (AE) and posterior (PE) BFS (in $\mu \mathrm{m}$ ).

3. Elevation of the thinnest point from the 7, 8 , and $9 \mathrm{~mm}$ posterior (PE) BFTE (in $\mu \mathrm{m}$ ).

2. Pachymetry indices:

1. PPI-average and PPI-maximum

2. ART-average (ART-Avg), and maximum (ART-Max).

The study adhered to the Tenets of the Declaration of Helsinki and was approved by the ethical committee of Watany Research and Development Center, Cairo, Egypt. Patient consent to review their medical records was not required by the ethical committee as this investigation was

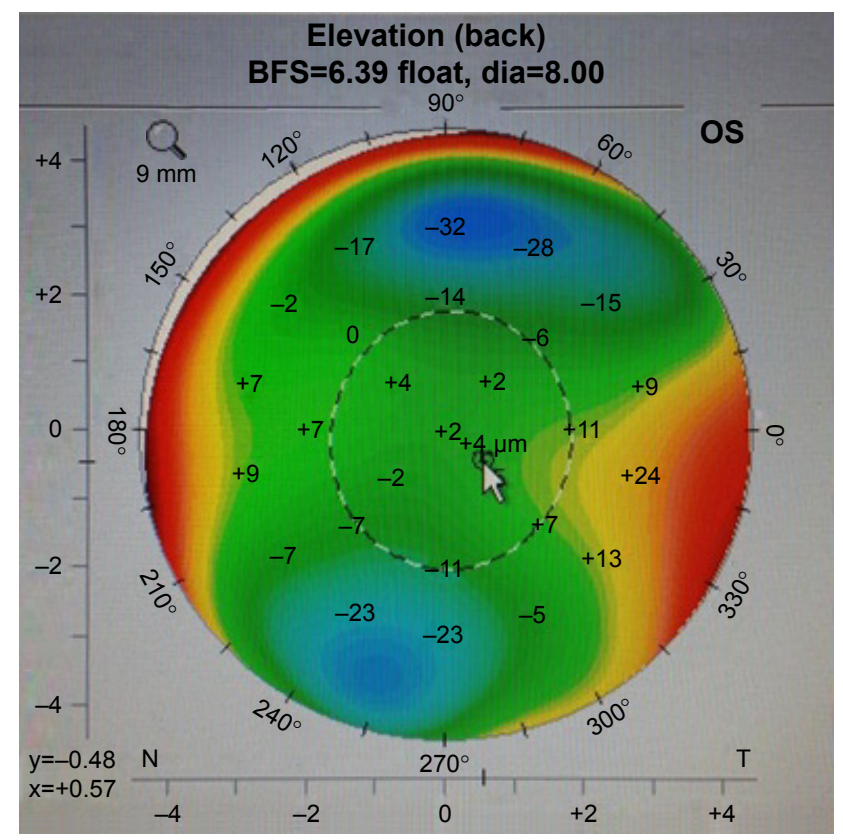

Figure I Getting the elevation of the thinnest point on mouse click at this exact point. Abbreviation: BFS, best-fit sphere. 
part of their routine preoperative evaluation with respect to the patient data confidentiality.

\section{Statistical analysis}

Compound indices were calculated using Microsoft Excel 2010 (Redmond, WA, USA). Statistical analyses were done using MedCalc Statistical Software version 14.8.1 (MedCalc Software bvba, Ostend, Belgium) and IBM SPSS Statistics version 23 (Armonk, NY, USA).

The tests were performed as follows: calculation of the mean, SD, unpaired $t$-test, chi-squared test, sensitivity, and specificity at different cutoff values, and AUROC. Logistic regression was done using the aforementioned 10 indices to find new indices with higher AUROC. Their AUROCs were compared with others using the DeLong et al method.

\section{Results}

The patients' average age was 29.2 \pm 8.8 (range 17.4-53.2) and 27.8 \pm 7.3 years (range 14-44.4) in normal and $\mathrm{KC}$ groups, respectively. There was no statistically significant difference between the 2 groups $(P=0.253)$. The ratios between right and left eyes were 53:50 and 40:33 in normal and $\mathrm{KC}$ groups, respectively $(P=0.777)$.

On revising the files in December 2015, no patient's diagnosis was changed. All eyes diagnosed as normal underwent laser refractive surgery and remained with stable postoperative refraction with no ectatic symptoms or signs. On the other hand, cases diagnosed as $\mathrm{KC}$ showed progression unless crosslinked.

Logistic regression using the 10 indices with highest AUROC from our published work ${ }^{12}$ resulted in 2 new indices with high AUROC at BFS of 8 and $9 \mathrm{~mm}$ diameters; Corneal Assessment Index from Relational thickness and other OCULUS values (CAIRO):

$$
\begin{aligned}
\text { CAIRO } 8 \text { Index }= & 5.0549+0.6392(\text { AE at } 8 \mathrm{~mm}) \\
& -0.02251(\text { ART-Max }) \\
\text { CAIRO } 9 \text { Index }= & 2.6835+0.6492(\text { AE at } 9 \mathrm{~mm}) \\
& -0.02134(\text { ART-Max })
\end{aligned}
$$

CAIRO indices included 1 of the elevation indices, which is AE, and 1 of the pachymetry indices which is ART-Max.

They indicate normal cornea if the value is $<0.5$ and $\mathrm{KC}$ for values $\geq 0.5$. The mean CAIRO 9 was $-3.70 \pm 2.63$ in normal corneas, $6.47 \pm 3.92$ in early $\mathrm{KC}$, and $29.33 \pm 13.3$ in established $\mathrm{KC}$. The mean CAIRO 8 was $-4.93 \pm 2.35$ in normal corneas, $4.28 \pm 3.72$ in early $\mathrm{KC}$, and $23.5 \pm 11.34$ in established KC. Table 1 presents the AUROC of the new CAIRO indices compared with the 10 indices with highest AUROC published in our previous study. ${ }^{12}$

\begin{tabular}{|c|c|c|c|c|c|c|c|}
\hline Indices & AUROC & $95 \% \mathrm{Cl}$ & Criterion & Sensitivity & Specificity & $\begin{array}{l}\text { AUROC } \\
\text { compared } \\
\text { with that of } \\
\text { CAIRO } 9 \text { (P) }\end{array}$ & $\begin{array}{l}\text { AUROC } \\
\text { compared } \\
\text { with that of } \\
\text { CAIRO } 8 \text { (P) }\end{array}$ \\
\hline CAIRO using $9 \mathrm{~mm}$ BFS & 0.997 & $0.973-1.0$ & $\geq 0.5$ & 95.89 & 97.09 & & 0.268 \\
\hline CAIRO using $8 \mathrm{~mm}$ BFS & 0.995 & $0.970-1.0$ & $\geq 0.5$ & 93.15 & 98.06 & 0.268 & \\
\hline ART-Max & 0.987 & $0.957-0.998$ & $\leq 412$ & 97.26 & 93.2 & 0.046 & 0.087 \\
\hline PPI-Max & 0.987 & $0.958-0.998$ & $>1.4$ & 91.78 & 98.06 & 0.033 & 0.074 \\
\hline $\begin{array}{l}\text { Elevation of the thinnest point } \\
\text { from the } 9 \mathrm{~mm} \text { anterior BFS }\end{array}$ & 0.979 & $0.945-0.995$ & $>7$ & 95.89 & 92.23 & 0.108 & 0.138 \\
\hline $\begin{array}{l}\text { Elevation of the thinnest point } \\
\text { from the } 8 \mathrm{~mm} \text { posterior BFS }\end{array}$ & 0.979 & $0.945-0.995$ & $>20$ & 86.3 & 100 & 0.017 & 0.024 \\
\hline PPI-Avg & 0.978 & $0.944-0.994$ & $>1.1$ & 87.67 & 98.06 & 0.038 & 0.049 \\
\hline $\begin{array}{l}\text { Elevation of the thinnest point } \\
\text { from the } 9 \mathrm{~mm} \text { posterior BFS }\end{array}$ & 0.977 & $0.942-0.994$ & $>22$ & 89.04 & 96.12 & 0.027 & 0.04 \\
\hline ART-Avg & 0.976 & $0.942-0.993$ & $\leq 496$ & 94.52 & 94.17 & 0.028 & 0.035 \\
\hline $\begin{array}{l}\text { Elevation of the thinnest point } \\
\text { from the } 7 \mathrm{~mm} \text { posterior BFS }\end{array}$ & 0.971 & $0.934-0.990$ & $>10$ & 87.67 & 100 & 0.049 & 0.061 \\
\hline $\begin{array}{l}\text { Elevation of the thinnest point } \\
\text { from the } 8 \mathrm{~mm} \text { anterior BFS }\end{array}$ & 0.968 & $0.930-0.989$ & $>5$ & 91.78 & 96.12 & 0.096 & 0.099 \\
\hline $\begin{array}{l}\text { Elevation of the thinnest point } \\
\text { from the } 7 \mathrm{~mm} \text { posterior BFTE }\end{array}$ & 0.953 & $0.910-0.979$ & $>10$ & 87.67 & 99.03 & $<0.001$ & $<0.001$ \\
\hline
\end{tabular}

CAIRO 8 and 9 indices had high sensitivity and specificity. Their AUROCs are statistically superior to most of

Table I The indices with highest AUROC

Abbreviations: $95 \% \mathrm{Cl}$, 95\% confidence interval of the AUROC; ART-Avg, Ambrosio's relational thickness average; ART-Max, Ambrosio's relational thickness maximum; AUROC, area under the receiver operating characteristic curve; BFS, best-fit sphere; BFTE, best-fit toric ellipsoid; CAIRO, Corneal Assessment Index from the Relational thickness and other Oculus values using $9 \mathrm{~mm}$ BFS (CAIRO 9) and $8 \mathrm{~mm}$ BFS (CAIRO 8); P from CAIRO indices, probability of chance that the AUROC of the index is less than that of CAIRO 9 or CAIRO 8 indices; PPI-Avg, pachymetric progression index average; PPI-Max, pachymetric progression index maximum. 
Table 2 Fallacies of each index included in the CAIRO indices

\begin{tabular}{lllllll}
\hline & PPI-Max & ART-Max & $\begin{array}{l}\text { Elevation of the thinnest } \\
\text { point from the } \mathbf{8} \mathbf{~ m m} \\
\text { anterior BFS }\end{array}$ & $\begin{array}{l}\text { Elevation of the thinnest } \\
\text { point from the } \mathbf{~} \mathbf{~ m m} \\
\text { anterior BFS }\end{array}$ & $\begin{array}{l}\text { CAIRO } 8 \\
\text { CAIRO 9 }\end{array}$ \\
\hline False diagnosis rate & $4.55 \%$ & $5.11 \%$ & $6.25 \%$ & $6.82 \%$ & $3.98 \%$ & $3.41 \%$ \\
\hline
\end{tabular}

Abbreviations: ART-Max, Ambrosio relational thickness in maximum meridian; BFS, best-fit sphere; CAIRO, Corneal Assessment Index from Relational thickness and other OCULUS values using $8 \mathrm{~mm}$ BFS (CAIRO 8 ) and $9 \mathrm{~mm}$ BFS (CAIRO 9).

the other indices and have the least rate of false diagnosis compared with each index included in the new formulae (Table 2; Figure 2).

The CAIRO indices were obviously statistically superior to some commonly used indices, that is, ART-Avg and posterior elevation of the thinnest point from BFS at $8 \mathrm{~mm}$ when trying to differentiate early $\mathrm{KC}(\mathrm{TKC}<2, \mathrm{n}=23)$ from normal corneas $(n=103)$ (Figure 3). However, there was no such significance between their high AUROC when used to differentiate established KC (TKC $=2-4, n=50)$ from normal corneas (Table 3 ).

\section{Discussion}

Elevation-based tomography became the invaluable tool for screening refractive surgery candidates for any risk of developing post-LASIK ectasia. It provides many $\mathrm{KC}$ indices with different sensitivity and specificity. Combined indices are sometimes more accurate than simple indices. ${ }^{6-8}$

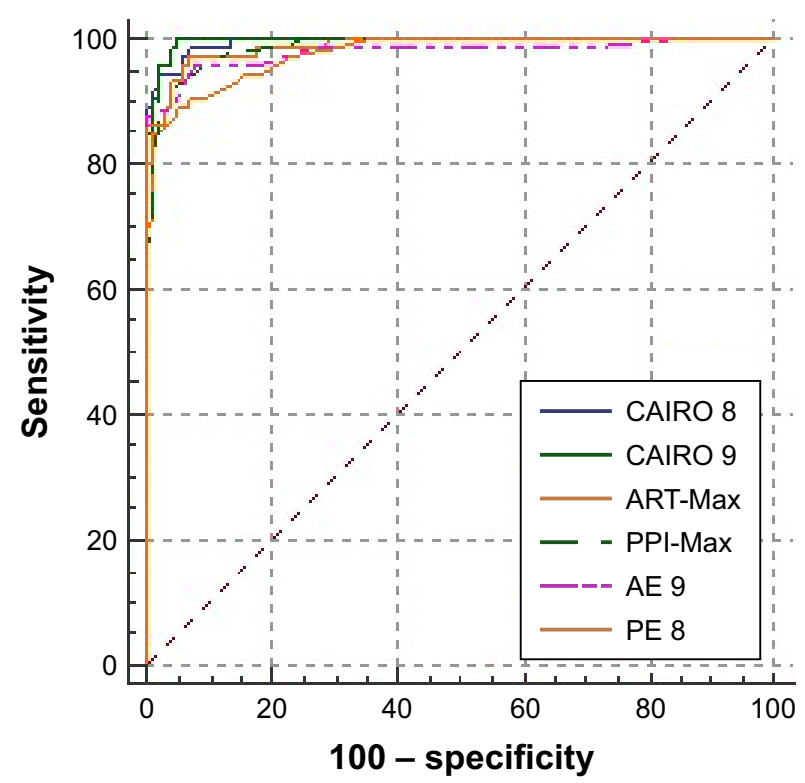

Figure 2 AUROC of CAIRO indices compared with the 4 indices of highest AUROC throughout all cases.

Abbreviations: ART-Max, Ambrosio's relational thickness maximum; CAIRO, Corneal Assessment Index from the Relational thickness and other Oculus values using $9 \mathrm{~mm}$ BFS (CAIRO 9) and $8 \mathrm{~mm}$ BFS (CAIRO 8); PPI-max, pachymetric progression index maximum; $A E$, anterior elevation from $9 \mathrm{~mm}$ BFS (AE 9) and $8 \mathrm{~mm}$ BFS (AE 8).
In a previous study, we evaluated the diagnostic accuracy (including both sensitivity and specificity) of $\mathrm{KC}$ indices with the use of different reference surfaces, at different diameters. ${ }^{12}$ The 10 indices with highest AUROC for diagnosing $\mathrm{KC}$ included the PPI-Max at a cutoff value of $>1.4$ and the combined index ART-Max at a cutoff value of $\leq 412$ ( 0.987 for both). These results were comparable with those of Ambrósio et $\mathrm{al}^{6}$ who reported that the most sensitive parameters were the combined indices ART-Avg and ART-Max (AUROC $=0.987$ and 0.983 , respectively). The AUROC of these 10 indices were statistically non-inferior to each other $(P>0.05)$. Meanwhile, all other indices were statistically inferior to at least 1 of these 10 indices. All the 10 indices were pachymetry and elevation indices, with no curvature indices. This matches the results of the previous studies. ${ }^{7,13,14}$

In the current study, we adopted a subgrouping of the $\mathrm{KC}$ group into 2 subgroups, instead of 3 in our previous published

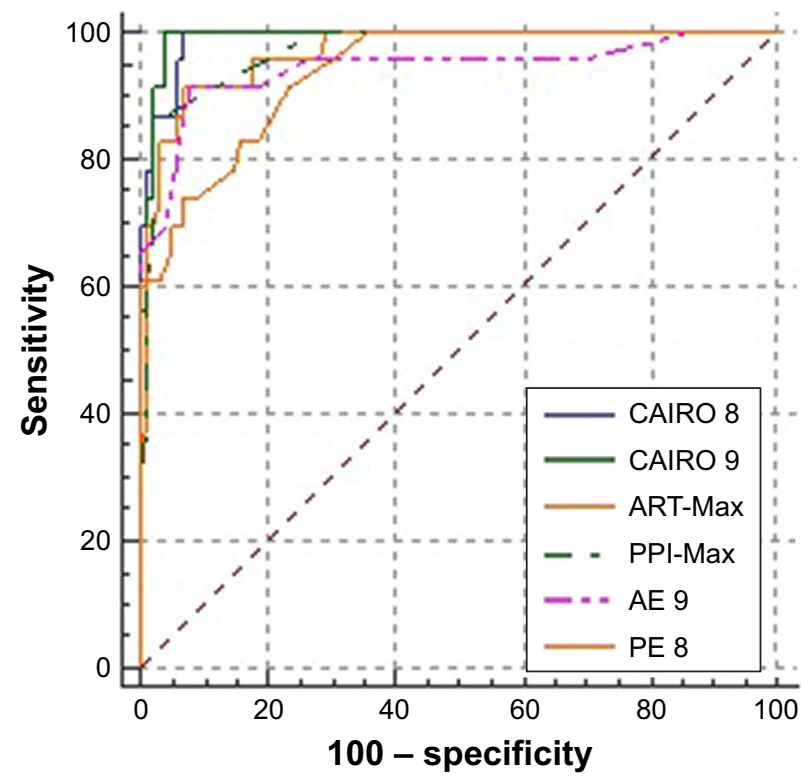

Figure 3 AUROC of CAIRO indices compared with the 4 indices of highest $A \cup R O C$ in differentiating early KC from normal corneas.

Abbreviations: ART-Max, Ambrosio's relational thickness maximum; AUROC, Area Under Receiver Operating Characteristic curves; CAIRO, Corneal Assessment Index from the Relational thickness and other Oculus values using $9 \mathrm{~mm}$ BFS (CAIRO 9) and $8 \mathrm{~mm}$ BFS (CAIRO 8); PPI-max, pachymetric progression index maximum; KC, keratoconus; $A E$, anterior elevation from $9 \mathrm{~mm} B F S$ (AE 9) and $8 \mathrm{~mm}$ BFS (AE 8). 
Table 3 AUROC of CAIRO indices and some of the conventional indices in both normal and each subdivision of KC groups

\begin{tabular}{|c|c|c|c|c|c|c|}
\hline \multirow[t]{2}{*}{ Indices } & \multicolumn{3}{|c|}{ TKC $<2(n=23)$ vs normal $(n=103)$} & \multicolumn{3}{|c|}{ TKC $2-4(n=50)$ vs normal $(n=103)$} \\
\hline & AUROC & $\begin{array}{l}\text { P-value when } \\
\text { compared with } \\
\text { CAIRO } 8 \\
\end{array}$ & $\begin{array}{l}\text { P-value when } \\
\text { compared with } \\
\text { CAIRO } 9\end{array}$ & AUROC & $\begin{array}{l}\text { P-value when } \\
\text { compared with } \\
\text { CAIRO } 8 \\
\end{array}$ & $\begin{array}{l}\text { P-value when } \\
\text { compared with } \\
\text { CAIRO } 9\end{array}$ \\
\hline CAIRO 8 & 0.989 & & 0.533 & 0.997 & & $0.34 I$ \\
\hline CAIRO 9 & 0.992 & 0.533 & - & 0.999 & 0.341 & \\
\hline ART-Avg & 0.934 & 0.028 & 0.033 & 0.996 & 0.651 & 0.135 \\
\hline ART-Max & 0.968 & 0.072 & 0.083 & 0.996 & 0.609 & 0.127 \\
\hline $\begin{array}{l}\text { Elevation of the thinnest point } \\
\text { from the } 8 \mathrm{~mm} \text { anterior BFS }\end{array}$ & 0.937 & 0.191 & 0.182 & 0.982 & 0.318 & 0.318 \\
\hline $\begin{array}{l}\text { Elevation of the thinnest point } \\
\text { from the } 8 \mathrm{~mm} \text { posterior BFS }\end{array}$ & 0.938 & 0.011 & 0.012 & 0.998 & 0.612 & 0.359 \\
\hline
\end{tabular}

Abbreviations: ART-Avg, Ambrosio relational thickness average; ART-Max, Ambrosio relational thickness maximum; AUROC, area under the receiver operating characteristic curve; CAIRO, Corneal Assessment Index from the Relational thickness and other Oculus values; TKC, Topographic Keratoconus Classification.

paper, ${ }^{12}$ as we found from our previous study that there were limited significant variations in the indices accuracy in already established KC starting from TKC grade 2 .

Although single-point values could differentiate between normal and keratoconic corneas, they suffer significant overlap. ${ }^{6,9}$ Many authors tried to overcome the shortcomings of these single-point values through complex systems. Maeda et $\mathrm{al}^{15}$ presented a classification that detects $\mathrm{KC}$ based on the analysis of 8 numerical topographic indices derived from the Placido-based topography. Smolek and Klyce ${ }^{10}$ designed a neural network approach that distinguishes $\mathrm{KC}$ suspect. Rabinowitz system uses 4 indices ${ }^{9}$ to distinguish normal from $\mathrm{KC}$ and provide a range for $\mathrm{KC}$ suspect. All these systems were based on complex indices in order to have both good sensitivity and specificity at the same time. However, these systems are solely confined to anterior surface topography, which has many confounding conditions. Recently, few tomographic-combined indices were suggested to overcome these confounding conditions like ART values ${ }^{6}$ and multimetric D values. ${ }^{8}$

This study calculated a new combined index "Corneal Assessment Index from the Relational thickness and other OCULUS values (CAIRO)" at BFS of different diameters ( 8 and $9 \mathrm{~mm}$ ) through a regression analysis. This formula combined the index of high sensitivity, ART-Max, with the anterior elevation. The advantages of the new indices are getting highest AUROC (CAIRO 9=0.997 and CAIRO 8= 0.995 ) (Table 1) with least false diagnosis rate $3.41 \%$ and $3.98 \%$ for CAIRO 9 and CAIRO 8, respectively (Table 2). It combines both pachymetric and elevation parameters and this could be the cause of its higher sensitivity and specificity.

The regression analysis lead to an accurate combined index that included the anterior elevation with the ART-max, but didn't incorporate the posterior elevation in its formula. This combination has its own specific advantage, as a previous study reported that posterior elevation could be variable with hyperopic individuals and nowadays there is an increasing percentage of hyperopic people asking for refractive surgery. ${ }^{16}$

When differentiating between normal and early $\mathrm{KC}$ $(\mathrm{TKC}<2)$, CAIRO indices were statistically superior to some of the conventional indices as ART-Avg and posterior elevation of the thinnest point from BFS at $8 \mathrm{~mm}$, both are considered of the gold standard indices in screening the refractive surgery candidates. ${ }^{6,17}$ On the other hand, there was no statistical significance in established $\mathrm{KC}$ ( TKC $=2-4)$.

Limitations of the current study are that it was done only with basic Pentacam model (Allegro Oculyzer I), which is still being used in many centers. Further studies on Pentacam $\mathrm{HR}$ are recommended and the validation of these indices on Pentacam HR is ongoing based on Randleman et al ${ }^{18}$ report that, for refractive surgical screening, regular and highresolution Scheimpflug imaging devices generated different objective values and the 2 devices are not interchangeable. It is recommended also to compare the accuracy of CAIRO indices to the new combined biomechanical index, which is based on deformation parameters and corneal thickness profile as it showed high accuracy in differentiating between normal and $\mathrm{KC}$ corneas. ${ }^{19}$

CAIRO indices will be beneficial in clinical use when the usual indices, including the ART-Max or the D indices, are suspicious or give conflicting results.

\section{Conclusion}

Proposed new corneal assessment indices (CASIRO 8 and CAIRO 9) have better sensitivity and specificity for $\mathrm{KC}$ 
detection than many other gold standard indices, especially in early $\mathrm{KC}$.

\section{Disclosure}

The authors report no conflicts of interest in this work.

\section{References}

1. Rabinowitz YS, Keratoconus RYS. Keratoconus. Surv Ophthalmol. 1998;42(4):297-319.

2. Belin MW, Zloty P. Accuracy of the PAR corneal topography system with spatial misalignment. Clao J. 1993;19(1):64-68.

3. Committee on Ophthalmic Procedures Assessment Cornea Panel, Cohen EJ(Chair): Corneal Topography. Ophthalmology. 1999;106: $1628-1638$

4. Belin MW, Khachikian SS, Ambrósio Jr R. Understanding Elevation Based Topography: How Elevation Data is Displayed. Elevation Based Corneal Tomography. 2nd ed. Clayton. Panama: Jaypee Highlights Medical Publishers; 2012:25-46.

5. Ramamurthy S, Reddy JC, Jhanji V. Topography and tomography in the diagnosis of corneal ectasia. Expert Rev Ophthalmol. 2015;10(3):215-228.

6. Ambrósio R, Caiado AL, Guerra FP, et al. Novel pachymetric parameters based on corneal tomography for diagnosing keratoconus. J Refract Surg. 2011;27(10):753-758. Epub 2011 Jul 29.

7. Faria Correia F, Ramos I, Lopes B, et al. Topometric and tomographic indices for the diagnosis of keratoconus. Int $J$ Keratoconus Ectatic Corneal Dis. 2012;1(2):92-99.

8. Muftuoglu O, Ayar O, Hurmeric V, Orucoglu F, Kilic I. Comparison of multimetric $\mathrm{D}$ index with keratometric, pachymetric, and posterior elevation parameters in diagnosing subclinical keratoconus in fellow eyes of asymmetric keratoconus patients. J Cataract Refract Surg. 2015;41(3): $557-565$.
9. Rabinowitz YS, Rasheed K. KISA\% index: a quantitative videokeratography algorithm embodying minimal topographic criteria for diagnosing keratoconus. J Cataract Refract Surg. 1999;25(10): $1327-1335$.

10. Smolek MK, Klyce SD. Current keratoconus detection methods compared with a neural network approach. Invest Ophthalmol Vis Sci. 1997;38(11):2290-2299.

11. Alió JL, Shabayek MH. Corneal higher order aberrations: a method to grade keratoconus. J Refract Surg. 2006;22(6):539-545.

12. Wahba SS, Roshdy MM, Elkitkat RS, Naguib KM. Rotating Scheimpflug imaging indices in different grades of keratoconus. J Ophthalmol. 2016;2016:6392472.

13. Ambrósio R, Nogueira LP, Caldas DL, et al. Evaluation of corneal shape and biomechanics before LASIK. Int Ophthalmol Clin. 2011;51(2): $11-38$.

14. Belin MW, Ambrósio R. Corneal ectasia risk score: statistical validity and clinical relevance. J Refract Surg. 2010;26(4):238-240.

15. Maeda N, Klyce SD, Smolek MK, Thompson HW. Automated keratoconus screening with corneal topography analysis. Invest Ophthalmol Vis Sci. 1994;35(6):2749-2757.

16. Kim JT, Cortese M, Belin MW, Ambrosio R, Khachikian SS. Tomography normal values for corneal elevation and pachymetry in a hyperopic population. J Clin Experiment Ophthalmol. 2011;2(2): 130-133.

17. Saad A, Gatinel D. Topographic and tomographic properties of forme fruste keratoconus corneas. Invest Ophthalmol Vis Sci. 2010;51(11): $5546-5555$.

18. Randleman JB, Akhtar J, Lynn MJ, et al. Comparison of objective and subjective refractive surgery screening parameters between regular and high-resolution Scheimpflug imaging devices. J Cataract Refract Surg. 2015;41(2):286-294.

19. Vinciguerra R, Ambrósio R, Elsheikh A, et al. Detection of keratoconus with a new biomechanical index. J Refract Surg. 2016;32(12): 803-810.
Clinical Ophthalmology

\section{Publish your work in this journal}

Clinical Ophthalmology is an international, peer-reviewed journal covering all subspecialties within ophthalmology. Key topics include: Optometry; Visual science; Pharmacology and drug therapy in eye diseases; Basic Sciences; Primary and Secondary eye care; Patient Safety and Quality of Care Improvements. This journal is indexed on Submit your manuscript here: http://www.dovepress.com/clinical-ophthalmology-journal

\section{Dovepress}

PubMed Central and CAS, and is the official journal of The Society of Clinical Ophthalmology (SCO). The manuscript management system is completely online and includes a very quick and fair peer-review system, which is all easy to use. Visit http://www.dovepress.com/ testimonials.php to read real quotes from published authors. 